\title{
CONTRIBUIÇÕES DA GEOGRAFIA ESCOLAR PARA A ABORDAGEM DA HISTÓRIA E CULTURA AFRO-BRASILEIRA E AFRICANA NO ENSINO FUNDAMENTAL ॥
}

\author{
Lidiane Aparecida Alves \\ Prefeitura Municipal de Uberlândia (PMU) \\ Email: lidianeaa@yahoo.com.br
}

Resumo: Para romper com visões estereotipadas sobre a África, os africanos, e os afrodescendentes, além do desconhecimento de uma grande parte da população brasileira sobre sua ancestralidade, bem como para contribuir com o rompimento da perpetuação das desigualdades e preconceitos que historicamente atingiu a população indígena e afrodescendente brasileira, os avanços legais são imprescindíveis. Neste sentido, ressalta-se a contribuição das Políticas de Ações Afirmativas para as Populações Negras, onde se insere a lei $n^{\circ} 10.639$, de 9 de janeiro de 2003, que incluiu no currículo oficial da Rede de Ensino o dia 20 de novembro como 'Dia Nacional da Consciência Negra' e a obrigatoriedade da temática "História e Cultura Afro-Brasileira", e a lei $n^{\circ}$ 11.645, de 10 março de 2008, que acrescenta à História e Cultura Afro-Brasileira a Indígena. Entretanto, não bastam os instrumentos legais, é preciso que as leis peguem e, sobretudo que sejam bem aplicadas. Assim, 
são vários os desafios para se trabalhar a temática "História e Cultura AfroBrasileira e Indígena", dentre os quais destaca-se a falta de formação e/ou orientação teórica sobre o assunto por parte de muitos professores, não somente de História, mas também de outras disciplinas, como a Geografia, que não é mencionada na legislação, mas que igualmente tem um grande papel para o entendimento e a mudança da sociedade. No nível da educação básica, nomeadamente no ensino fundamental II, ressalta-se a pertinência de que os conteúdos inerentes à "História e Cultura AfroBrasileira e Indígena" sejam trabalhados pelas diferentes áreas do conhecimento, abordando a cultura (as danças, as músicas, os ritmos, festas e as cores alegres e vibrantes com que os africanos se vestem e se pintam etc) em suas várias perspectivas, considerando suas variações, as influências e transformações que sofreram. Além disso, também devem ser abordados temas pouco explorados como as religiões africanas, assim como deve-se avançar para além dos aspectos culturais e considerar questões como a participação dos negros na pesquisa, ciência e tecnologia. Diante do exposto, e considerando a vivência em sala de aula do ensino fundamental II, o presente relato aborda as dificuldades para a implementação das leis 10.639/2003 e 11.645/2004, sobretudo considerando a necessidade do desenvolvimento de trabalhos, pelo menos, interdisciplinares. Ressalta-se que no âmbito da disciplina Geografia, sobretudo considerando os conteúdos trabalhados nos sétimos anos, nomeadamente no que concerne a formação da população busca-se tratar da "História e Cultura Afro-Brasileira e Indígena". Neste sentido, ressalta-se a busca pelo conhecimento das origens, isto é, da ancestralidade africana, tanto nos aspectos genéticos como culturais, além disso, aborda-se a forma de desenvolvimento excludente, que explica as atuais desigualdades étnicas e socioeconômicas presente tanto na África como no Brasil.

\section{Introdução}

A questão das relações étnico-raciais, no contexto brasileiro, emergiu e persiste, sobretudo, desde século XVIII, reproduzindo, de maneira institucionalizada ou não, ao longo de três séculos processos de exclusão material e simbólica. Isto é, ainda persiste a influência dos fatos passados na conjuntura da atual sociedade brasileira.

Recentemente, no século XXI, ocorreu o reconhecimento formal da existência de tal questão, assim como a proposição de instrumentos/iniciativas para a sua superação e, consequentemente para a promoção da equidade entre todos os sujeitos, independente de suas características étnico-raciais, físicas, de gênero ou 
sociais. Afinal, a luta pela igualdade étnico-racial está intrinsicamente relacionada com as lutas contra as opressões de gênero e sociais.

Desta forma, o reconhecimento da existência dos processos de discriminação, que desencadeiam uma série de perversidades como a reprodução e acentuação das desigualdades socioeconômicas e de gênero, assim como a proposição de instrumentos para a promoção de igualdades foi um avanço inegável.

Entretanto, para que as mudanças sejam materializadas, além dos instrumentos institucionais, que fornecem o embasamento formal é preciso que estes sejam difundidos e colocados em prática, a partir da criação de condições para conhecimento dos fatos históricos, reflexão crítica acerca das consequências das condições historicamente reproduzidas, bem como propiciar o resgate/a criação e/ou a mudança de hábitos e valores, que devem ser repassados às próximas gerações.

Neste sentido, ressalta-se a potencialidade da escola e do processo de ensinoaprendizagem, especialmente das disciplinas História e Geografia, que têm como objetivo principal o estudo das sociedades considerando determinados tempo e espaço. A despeito da preponderância de tais saberes no estudo da história e da cultura das Áfricas, dos afro-brasileiros e dos indígenas, é sabido que o processo educativo pautado nas relações étnico-raciais e na superação estrutural do preconceito e racismo transborda a fronteira disciplinar, requerendo um trabalho com maior articulação, de modo que os projetos didáticos, ao serem realizados envolvendo vários professores e conteúdos curriculares, propiciam o alcance não somente dos objetivos didáticos, mas também objetivos sociais.

Portanto, muito além do que simplesmente cumprir as leis $n^{\circ} 10.639 / 03$ e 11.645/2008, o foco das propostas pedagógicas deve ser o rompimento de paradigmas na perspectiva das relações econômicas e sociais, de uma sociedade que manteve a escravidão por um longo período e, por isso ainda a despeito da ideologia de uma "democracia racial" são visíveis ações preconceituosas e discriminadoras. Afinal,

O padrão brasileiro de relação social, ainda hoje dominante, foi construído por uma sociedade escravista, ou seja, para manter o 'negro' sob a sujeição do 'branco'. Enquanto esse padrão de relação social não for abolido, a distância econômica, social e política entre o 'negro' e o 'branco' será grande, embora tal coisa não seja 
reconhecida de modo aberto, honesto e explícito. (FERNANDES, PEREIRA E NOGUEIRA, 2006, p. 172).

Diante da riqueza natural, cultural e pluralidade das sociedades africana e brasileira, há uma gama encaminhamentos possíveis para abordar a "História da África" assim como os seus intercruzamentos com "Cultura Afro-Brasileira", de modo que é necessária a realização de um "recorte" do assunto a ser trabalhado, com vistas a assegurar melhor apreensão e resultados em torno da temática escolhida.

De tal modo, considerando a realidade dos alunos, a possibilidade de abordagem interdisciplinar, bem como a necessidade de fortalecimento de valores e sentimentos como a autoestima, selecionou-se como recorte a diversidade cultural brasileira, fruto da miscigenação étnico-cultural de povos oriundos de diversas partes do mundo, que apropriaram e ressignificaram manifestações culturais que hoje são parte de nossa identidade sociocultural.

Isso posto, o presente artigo tem como objetivo relatar o desenvolvimento de um projeto que contempla a questão da "História e Cultura Afro-Brasileira" no âmbito do ensino fundamental, com vistas a construção de uma visão crítica. Além disso, destaca as dificuldades para a implementação da lei 10.639/2003.

Para tanto, a metodologia utilizada consistiu em uma revisão de literatura associada a pesquisas documentais, tendo em consideração a vivência em sala de aula e no desenvolvimento do projeto sobre a diversidade cultural brasileira, ao longo do ano de 2017, considerando os conteúdos curriculares do ensino de Geografia, no âmbito do ensino fundamental II.

\section{A abordagem da história e cultura afro-brasileira e africana no ensino} fundamental como encaminhamento para a transformação socioespacial

Inicialmente cabe ressaltar a pertinência do conhecimento da história para compreensão do passado e, sobretudo do presente, que nas palavras de Santos (2006) apresenta-se "ao mesmo tempo concluído e inconcluso, num processo sempre renovado" pelo sujeito atuante na produção da nova história para o futuro que se projeta. Ainda com base no autor citado, cabe destacar a influência dos aspectos do passado no presente e das ações presentes no futuro. 
O presente não é um resultado, uma decorrência do passado, do mesmo modo que o futuro não pode ser uma decorrência do presente, mesmo se este é uma "eterna novidade", no dizer de S. Borelli (1992, p. 80)134. O passado comparece como uma das condições para a realização do evento, mas o dado dinâmico na produção da nova história é o próprio presente, isto é, a conjunção seletiva de forças existentes em um dado momento. $\mathrm{Na}$ realidade, se o Homem é Projeto, como diz Sartre, é o futuro que comanda as ações do presente. (SANTOS, 2006, p.224).

Neste sentido, é grande a pertinência de se conhecer a nossa história para se fortalecer, lutar e mudar a realidade, afinal, como afirma Hobsbawm (1917, p. 186) "não há povo sem história ou que possa ser compreendida sem ela". Ou ainda de acordo com Saviani (2008, p.151).

[...] é pela história que nós nos formamos como homens; que é por ela que nós nos conhecemos e ascendemos à plena consciência do que somos; que pelo estudo do que fomos no passado descobrimos, ao mesmo tempo, o que somos no presente e o que podemos vir a ser no futuro, o conhecimento histórico emerge como uma necessidade vital de todo ser humano. Tendo em vista que a realidade humana de cada indivíduo se constrói na relação com os outros e se desenvolve no tempo, a memória se configura como uma faculdade específica e essencialmente humana e atinge sua máxima expressão quando se manifesta como memória histórica.

Em um país multi-étnico e multi-cultural como o Brasil, a compreensão da pluralidade que constitui a cultura brasileira requer o conhecimento de várias culturas, dentre as quais destaca-se a cultura africana, que com o passar dos anos se miscigenou com as culturas indígenas e europeias, para a formação da cultura brasileira.

Assim, ao resgatar a descendência do povo brasileiro, especialmente considerando os afrodescendentes, ou seja, o povo que é descendente, que provém por geração, do povo africano. Busca-se nutrir um sentimento de orgulho e empoderamento, na perspectiva do reconhecimento e valorização das riquezas naturais, culturais, beleza e força dos povos da África, que foram submetidos à 
condição de escravos, mesmo que fossem originalmente guerreiros(as $)^{4}$, reis e rainhas.

Além disso, busca-se romper com o Anibal Quijano (2009) chamou de colonialidade do saber. De tal modo, a abordagem da história, da construção do mundo e do saber ocorre sob uma perspectiva, que não seja a eurocêntrica e etnocêntrica, que não reconhece, mas inferioriza os modos de vida que são diversos aos europeus; enfatiza-se que o continente africano não se restringe às famílias famintas e miseráveis, epidemias, guerras e os safáris, mas consiste em um continente rico no âmbito histórico-político-social e cultural; que os povos africanos trazidos como escravos pertenciam à varias etnias, nações, línguas e culturas ${ }^{5}$; que condição atual da nossa sociedade, em muito é reflexos do que ocorreu há tempos e o que pode ser no futuro, igualmente depende do que das ações de agora.

Tal processo é lento, bem como abarca vários desafios dentre os quais destaca-se a falta de formação e/ou orientação teórica sobre o assunto por parte de muitos professores de várias disciplinas, como a História e a Geografia, que não é mencionada na legislação, mas que por serem disciplinas intrinsecamente relacionadas, conforme Élisée Reclus havia escrito, há um século, geografia é a história no espaço e a história é a geografia no tempo, (SANTOS, 2006), tais saberes, têm igualmente um grande papel para o entendimento do passado, das circunstâncias atuais e para a mudança da sociedade.

Além da história geral da qual somos parte, individualmente, também temos uma história, a nossa história, cuja compreensão é fundamental para a construção da nossa identidade, dos nossos valores e dos nossos objetivos. A busca pelo autoconhecimento, considerando tanto o conhecimento da história individual como da história do lugar onde vive, permite a compreensão das raízes históricas da realidade

\footnotetext{
${ }^{4}$ Desde o Egito antigo, passando pela Núbia, Nigéria, Congo, Ghana, Guiné Bissau, África do Sul e Benin. Existiram guerreiras como as "Amazonas do Daomé", também conhecidas como as guerreiras Mino, um dos poucos exércitos de mulheres, documentado da história moderna.

5 Segundo Reginaldo Prandi (2000, p. 53): "A origem dos africanos trazidos para o Brasil dependia também, e especialmente, de acordos e tratados realizados entre Portugal, Brasil e potências europeias, sobretudo a Inglaterra". Além disso, considerando o destino no Brasil, de acordo com Prandi (2000) a atividades econômicas predominantes em cada momento determinavam o destino dos africanos, de modo que até o século XVIII, para atender a economia canavieira, o principal destino era o Nordeste, especialmente Pernambuco e Bahia, posteriormente com a mineração o tráfico foi direcionado a região Sudeste, sobretudo Minas Gerais.
} 
socio-cultural e, portanto a conscientização que possibilita atuar para mudar as situações de opressão.

Entretanto, em virtude da existência de muitas lacunas, o conhecimento destas histórias, do povo e individual, requer a valorização da oralidade, sobretudo dos mais velhos. A valorização da oralidade, por meio da arte de guardar e ensinar as crenças, lendas, canções, costumes, informações (griots) e dos mais velhos (cota), por si só faz parte da tradição africana, enquanto na cultura ocidental que os jovens são valorizados demasiadamente.

A tradição da oralidade está presente na literatura africana, o autor Mia Couto, por exemplo, explora estes recursos e por meio de seus textos literários apresenta as angústias e as identidades dos vários povos africanos.

Especialmente, considerando o contexto atual em que o processo de globalização implica no enfraquecimento de valores e relações entre as pessoas e destas com o ambiente. O processo de conscientização sobre a ideia de cidadania, de cooperação e de cuidado com o espaço torna-se fundamental para fortalecer as relações pessoais, de pertencimento, para mudar a forma de consumo e relação com o lugar etc.

Portanto, partindo dos fundamentos de Paulo Freire e de Vygostsky, no sentido da potencialidade do processo ensino-aprendizagem para a transformação individual e social e, que este processo ocorre dialogicamente a partir da interação entre os sujeitos. No nível da educação básica, nomeadamente no ensino fundamental II, sobretudo considerando os conteúdos trabalhados nos sétimos anos, nomeadamente no que concerne a formação da população é que se tem trabalhado mais enfaticamente a questão da história da cultura afro-brasileira, buscando pelo conhecimento das origens, isto é, da ancestralidade africana, bem como valorizando a diversidade cultural do Brasil.

Cabe aqui ressaltar que apesar do papel da Geografia, no estudo da formação da população brasileira, as atividades inerentes a abordagem da diversidade cultural envolvem outras disciplinas, assim como estimulam os alunos a discutir questões inerentes às temáticas como a mestiçagem, o preconceito e a construção da identidade sociocultural. 
Dentre tais atividades destacam-se: as seções de filmes acompanhadas de rodas de conversa sobre as questões étnico-raciais e valores (como respeito, solidariedade); estudo de textos sobre a cultura brasileira e africana, a exemplo do valor da história oral e do conhecimento dos mais velhos; a recriação da arte afrobrasileira, a construção de artesanato da cultura africana (Abayomi, bonecas de nó ${ }^{6}$ e máscaras) e afro-brasileira; entre outros, para exposição na escola.

A finalização das atividades, como forma de ampliar seu alcance, não poderia ser de outra forma, senão em evento cultural aberto à comunidade, onde além da apresentação dos trabalhos desenvolvidos pelos estudantes como os artesanatos, música, da dança, da poesia, rodas de capoeira etc. ocorre a realização da eleição do "Rei e da Rainha da Beleza Brasileira" da escola X, uma Escola Municipal de Uberlândia.

\section{Considerações finais}

A escolha do recorte acerca da diversidade cultural brasileira tem como fundamento a necessidade de maior conhecimento e valorização da riqueza cultural do Brasil. Além disso, a partir das apresentações culturais, objetiva que os alunos reconheçam suas potencialidades e habilidades, assim como valorizem as culturas africana e brasileira/local.

Quanto aos resgates das histórias coletiva e individual, o intuito é além do fortalecimento do sentimento de pertencimento ao bairro, ao local onde a vida acontece, é sua valorização e busca por melhorias, especialmente em relação ao cuidado com a limpeza e preservação dos espaços privados e públicos.

Portanto, ressalta-se a potencialidade do conhecimento das raízes, dos antepassados tem para a transformação social e para o empoderamento a partir do reconhecimento e valorização, enquanto personagem/autor de histórias coletiva e individual, que estão em permanente construção e, portanto ainda têm um final em aberto.

\footnotetext{
${ }^{6}$ As bonecas de nó são símbolo de resistência, sendo que o termo Abayomi, significa 'Encontro precioso' em lorubá, uma das maiores etnias do continente africano. Informação disponível em: < http://www.afreaka.com.br/notas/bonecas-abayomi-simbolo-de-resistencia-tradicao-e-poderfeminino/>.
} 


\section{Referências}

BRASIL. Lei 10.639, de 09 de janeiro de 2003. Altera a Lei n. 9.394, de 20 de dezembro de 1996, que estabelece as diretrizes e bases da educação nacional, para incluir no currículo oficial da Rede de Ensino a obrigatoriedade da temática 'História e Cultura Afro-Brasileira', e dá outras providências. Diário Oficial [da República Federativa do Brasil], Brasília, DF, 10 dez. 2003. P. 1.

BRASIL. Ministério da Educação. Diretrizes Curriculares Nacionais para a Educação das Relações Étnico-raciais e o Ensino de História e Cultura Afrobrasileira e Africana. Brasília: MEC/SECAD, 2004.

BRASIL. Ministério da Educação. Plano Nacional de Implementação das Diretrizes Curriculares Nacionais para a Educação das Relações Étnico-raciais e o Ensino de História e Cultura Afro-brasileira e Africana. Brasília: MEC/SECAD, 2009.

CASTRO, T. de. África: geohistória, geopolítica e relações internacionais. Rio de Janeiro, Freitas Bastos, 1979.

CHAGAS, W. F. História e Cultura Afro-Brasileira e Africana na Educação Básica da Paraíba. Educ. Real. vol.42 no.1 Porto Alegre Jan./Mar. 2017. Disponível em <http://dx.doi.org/10.1590/2175-623661125>. Acesso em 29 set. 2017.

FERNANDES, F. A integração do negro na sociedade de classes. $3^{a}$ ed. São Paulo: Ática (Ensaios 34). 1978.

FERNANDES, F.; PEREIRA, J. B. B.; NOGUEIRA, O. A questão racial brasileira vista por três professores. Revista USP, São Paulo, n. 68, p. 168-179, dez./fev. 2005-2006.

HOBSBAWM, E.. Todo o povo tem história. In: Sobre história: ensaios

São Paulo: Companhia das Letras, 1997. p. 185-192.

LIMA, A. B. História da África em sala de aula: diversidade e tradição oral. In: ROSSATO, L.; SILVA, C. B. da; SILVA, M. da (Org.). Experiência de Ensino de História no Estágio Supervisionado. Florianópolis: Ed. da Udesc, 2011. p. 289307.

MACHADO, C. E. D.; LORAS, A. B. Gênios da humanidade: ciência, tecnologia e inovação africana e afrodescendente, EDUEL, Londrina, PR, 2017.

SANSONE, L. Da África ao Afro: uso e abuso da África entre os intelectuais e na cultura popular brasileira durante o século XX. Afro-Ásia, 27, p.249-250. Salvador, Centro de Estudos Afro-Orientais (CEAO), 2002.

SANTOS, M. A Natureza do Espaço: Técnica e Tempo, Razão e Emoção - 4. ed. São Paulo: Editora da Universidade de São Paulo, 2006 
SAVIANI, D. História da história da educação no Brasil: um balanço prévio e necessário. EccoS Revista Científica, vol. 10, núm. p. 147-167. Esp, julho, 2008. 